\title{
Preventing Behavioral-Risks Incidence among School Children: The Role of School-Based Health Promotion Program
}

\author{
Raymond 0. Chimezie ${ }^{1}$, Marychristiana E. Uzochukwu² \\ ${ }^{1}$ Health for Schools \& Community Foundation, Richmond, USA \\ ${ }^{2}$ School of Nursing, College of Health and Human Sciences, North Carolina A\&T State University, Greensboro, USA \\ Email: norbels10@yahoo.com, mcuzochu@ncat.edu
}

How to cite this paper: Chimezie, R.O. and Uzochukwu, M.E. (2021) Preventing Behavioral-Risks Incidence among School Children: The Role of School-Based Health Promotion Program. Journal of Biosciences and Medicines, 9, 155-169.

https://doi.org/10.4236/jbm.2021.98013

Received: July 6, 2021

Accepted: August 23, 2021

Published: August 26, 2021

Copyright $\odot 2021$ by author(s) and Scientific Research Publishing Inc. This work is licensed under the Creative Commons Attribution International License (CC BY 4.0).

http://creativecommons.org/licenses/by/4.0/

\begin{abstract}
This article addresses the important role school health education program can play in reducing youth risky behaviors that lead to incarceration, diseases and fatalities or that impact their academic performance in school. Children growing up are at risks of exposure to different behaviors and common social influences which if unchecked result in unexpected health consequences common among youth in America today. According to US Centers for Disease Control \& Prevention, the six leading behaviors that cause death, disability, and social problems among American children are: unintentional injuries and violence, alcohol and drug use, tobacco use, unhealthy diets, inadequate physical activities, and sexual behaviors and diseases. This article shows that school health program: 1) can provide the foundation for children to learn desired healthy behaviors in order to preserve life, 2) protects the future of children and that of the nation, 3) can teach students skills to recognize risky behaviors and resist them, 4) can boost community efforts to achieve desired health behaviors, 5) closes socio-economic gaps that interfere with basic nurturing of children, and 6) finally links local stakeholders as partners in promoting community safety. Through review of literature, the authors found that it costs $(\$ 588)$ daily or $(214,620)$ annually to incarcerate a juvenile and only $\$ 75$ daily for the cost of individualized community-based services. The cost to New York is over $\$ 900,000$, yet does not address the causative issues. The authors recommend that schools teach comprehensive school health from kindergarten to grade 12 and employ health educators to support teachers teach health promotion and education.
\end{abstract}

\section{Keywords}

School Health, Health Promotion, Youth Health, Youth Behavioral 
Risk-Factors, Health Education, Comprehensive School Health

\section{Introduction}

Every day all over the United States, over 55 million children from prekindergarten to grade 12 are in American public and private schools being educated by over 3.7 million teachers according to the National Center for Education Statistics [1] [2]. Among this population area sizeable number of school children who come from single household families with no adult to supervise them for the most time after school. Children within these ages undergo remarkable biological and social changes that profoundly impact their health and economic well-being as they group into adulthood [3]. Childhood and adolescence are critical for public health hence our schools should take an active part in teaching and exposing to healthier lifestyles. According to the U.S. Centers for Diseases \& Prevention [4], schools have direct contact with more than $95 \%$ of our nation's young people aged 5 to 17 years... for about 6 hours per day and up to 13 critical years of their social, psychological, physical, and intellectual development. With American tax payers leaving their children under the care of our school system with 3.7 million teachers for these numbers of hours and years, why are American children still at the risks or death from preventable behaviors related causes of death and disabilities? American children die daily from preventable behavior related causes such as unintentional injuries and violence; sexual behaviors related to unintended pregnancy and sexually transmitted diseases, including HIV infection, alcohol and other drug use, tobacco use, unhealthy dietary behaviors, inadequate physical activity [5]). In 2019, 696,620 children were arrested in the U.S., representing an arrest every 45 seconds despite a 62 percent reduction in child arrests between 2009 and 2019 (Children's Defense Fund, 2020) [6]. According to the ACLU [7], nearly 60,000 youth under age 18 are incarcerated in juvenile jails and prisons in the United States. Snatching this number of children from the school system and moving them to the juvenile system clearly indicates a critical missing gap in the way American school system runs. Through literature reviews, the authors explored the significance of school health program in promoting children's health, improving general education and ensuring proper physical and emotional development. They further explored the effectiveness of early exposure of children to healthy habits as well as well as the motivation for the establishment of the Whole School, Whole Community, Whole Child Model [WSCC] in 2015 by the U.S. Centers for Disease Prevention and Control (CDC) [8].

\section{Youth Risky Behaviors: A Public Health Problem}

Youth risky behaviors pose a serious concern to public health because it affects children's educational achievement, health and wellness, the quality of national 
labor force, creates safety concerns for the community, and a great cost to tax-payers. Children incarcerated as a result of behavioral crimes are deprived of the opportunity for full development, their health and wellbeing undermined, and exposed them to anger, physical abuse and violence. In 2017, 40\% of high school students had engaged in sexual intercourse, 39\% texted or emailed while driving, 30\% used alcohol, 23\% had asthma, 20\% used marijuana, 16\% were overweight, $15 \%$ had obesity, $14 \%$ inappropriately used prescription pain medicine, $13 \%$ used an electronic vapor product, $9 \%$ smoked cigarettes, and $7 \%$ had attempted suicide [2]. The 2019 National Survey on Drug Use and Health, revealed that an estimated 414,000 adolescents ages 12 to 17 (1.7 percent of this age group) had alcohol use disorder (AUD). This number includes 163,000 males (1.3 percent of males in this age group) and 251,000 females (2.1 percent of females in this age group) [9]. Tobacco alone kills prematurely and claims over 8 million lives annually worldwide, with 7 million dying from direct tobacco use [10]; shortens life expectancy by 10 years, and puts 5.6 million American children at a risk of one type of health problems or the other [11]. The CDC [12] reports that 1 in 5 high school students reported being bullied in the school property in 2019, about 13 children are victims of homicide every day in the US; about 1100 are treated in emergency departments for nonfatal assault-related injuries. Accordingly, treating youth violence is estimated to cost over $\$ 20$ billion annually. Both the costs and health consequences of youth risky behaviors are issues of concern and demand serious attention. Schools can play a role in reducing the number of juvenile crimes and incarceration by incorporating school-based health programs to make children aware of the consequences of risky health behaviors.

\section{Literature Review}

Evidence abounds in literature that school health promotion program helps children achieve better in school, learn healthier habits, and ultimately live healthily in the future. Attitudes developed in childhood will follow them to adulthood and may be very difficult to change. Bad attitudes have consequences that may result in injuries, deaths, or diseases [5] [11]. Accordingly, the World Health Organization [13] school-based health program is a multifaceted response to students' health needs and can be used to prevent some non-communicable disease risk factors such as tobacco use, physical inactivity, alcohol, and poor nutrition as well reduced health disparities in the population. The foregoing paragraphs will look into the early history of school-based health promotion, its role and significance, the Whole school, Whole community, Whole child model, and cost associated with youth incarceration.

\subsection{Early Foundation to Minimize Behavioral Health-Risks}

As early as the 1850s, the Sanitary Commission of Massachusetts headed by Lemuel Shattuck produced a landmark report that implicated the role schools 
"could play in controlling communicable disease with their 'captive audience' of children and young people". The report otherwise known as the Lemuel Shattuck Commission Report 1850 [14] set the milestone in school health by declaring as follows:

Every child should be taught early in life that, to preserve his own life and his own health and the lives and health of others, is one of the most important and constantly abiding duties. By obeying certain laws or performing certain acts, his life and health may be preserved; by disobedience, or performing certain other acts, they will both be destroyed. By knowing and avoiding the causes of disease, disease itself will be avoided, and he may enjoy health and live; by ignorance of these causes and exposure to them, he may contract disease, ruin his health, and die. Everything connected with wealth, happiness and long life depends upon health; and even the great duties of morals and religion are performed more acceptably in a healthy than a sickly condition (pp. 178-179).

Children's beliefs and behaviors are shaped during their formative years by the dominant behaviors in their environment and such behaviors tend to persist well into their lives [15]. Children who learn and practice healthier behaviors are more likely to have a higher academic achievement and success. When opportunities to learn a healthier lifestyle are offered to children at an early stage in school, it increases their likelihood to adopt healthier lifestyles and sustain it to their adulthood. Using the school setting to teach healthier lifestyles has an impact on the lives of the students' individual families and the whole community [16]. It will help students to recognize health risks of certain behaviors and so take active actions against it. Such was the outcome positively expressed at the inauguration of the School Health Education and Promotion program in Richmond, California, by Dr. Raymond Chimezie "After our anti-smoking campaign and awareness, many students reported talking to their parents about the dangers of smoking and the effects of second-hand smoke to people around them" [17]. This shows how effective integrated school health program can impact positively the health of the children and their families.

\subsection{School Health Protects the Future of Children and the Nation}

Children represent the future, and ensuring their healthy growth and development ought to be a prime concern of all societies. School therefore "is a unique setting for preventive interventions, and school years an important period to establish healthy behaviors that will contribute to a lifetime of health promotion" [18]. It should be re-emphasized that education is child-centered and thus should be fully concerned with the development of the whole child as a productive individual and good member of the society. No aspect of education that contributes to the whole development of a child should be ignored. Therefore integrating health education and promotion in public education will help improve every child's cognitive, physical, social, and emotional development [19]. It is worthy of note that schools not teaching and promoting healthy behaviors 
to children are depriving them the opportunity to live well, thrive, and accomplish their full potentials even to the next generations. Our schools offer a unique opportunity to teach and promote healthy behaviors to children from kindergarten (5-year-old) to graduating from grade 12 (17-year-old). The Institute of Medicine recommends that we must "strengthen schools as the heart of health" [14] [20]. Hence it defined comprehensive school health programs as an integrated set of planned, sequential, school-affiliated strategies, activities, and services designed to promote the optimal physical, emotional, social, and educational development of students [21]. The question is, "How could children pre-k to grade 12, learn healthier behaviors if our schools do not integrate and teach health promotion in their education curricula?" Should health promotion not be part of children's regular education for their development educationally and health wise? Neglecting this essential component in the development of any child, is surely watching them wallow in ignorance and become conscripted into the destructive American juvenile system for just making simple childlike mistakes. Education and health are intertwined, therefore schools offer children the foundation for good behaviors that promote their health and ensure healthier lifestyles in their adulthood. By extension, the school is another family for children and hence should fill in the gap created by single or absentee parenthood in any child's development or nurturing stage. Doing this reduces the prevalence of preventable behavioral risks that expose children to injuries, diseases, criminalities as well as increase the number of youth entering the nation's labor force.

\subsection{Promotes Knowledge-Based and the Environment for Better Behavior Formation}

Children in school are in the formative stage of their lives; they are not fully developed and often can act very emotionally. Behaviors of children are learned or determined by factors such as knowledge of the implications of the intended behaviors and the dominant environment of the child. An inclination to any type of behavior has been determined by Galen, David, \& Nilka [22] to be linked to internal, knowledge or external factors, social support that are instrumental in understanding behavior. These determine whether the individual initiates or avoids the anticipated behavior. According to the authors, the internal factors include, knowledge about risk factors and risk reduction, attitudes, beliefs, and core values $(A B C)$, social and life adaptation skills, psychological disposition (self-efficacy) and physiology; while the external factors include social support, media, socio-cultural, economic, and political factors, biologic, healthcare system, environmental stressors, and societal laws and regulations.

School health education and promotion programs will teach students skills and educate them on how to recognize the common risky behaviors that contribute to death, disability, and social problems among youth and adults in the United States [23]. It will support students to grow into healthy and productive adults by focusing on their physical, emotional, social, and educational development from kindergarten through grade 12. 


\subsection{School-Based Health Builds Synergy for School and Community Health Improvement}

A coordinated school health program provides a way to address the needs of the whole child by effectively connecting health with education and involving community in the process. This coordinated approach provides the framework for families, communities, and schools to work together to improve students' health and capacity to learn. It makes both the school and community to be co-partners in supporting the child. Furthermore, it has the capacity to promote healthy behavior, improve students' health, safety, and wellnesses, and increases students' readiness to learn, reduce absenteeism and involvement in risky behaviors.

In the early 1980s, school health programs focused on health education, health services and a healthy environment. Today, school health programs have a comprehensive approach hinging on eight components such as health education, physical education, health and safe school environment, nutrition services, community services, health promotion for staff, community and family health involvement, and counseling, psychology, and social services [24]. This focuses on the wellbeing of the whole child with whole community support, thereby enabling schools, communities and local stakeholders to work together to improve the health and wellbeing of young children while in school and support a healthier adult life. When schools run programs that involve families, much positive gains are made. For instance, it is on record that schools that adopt The Iowa Strengthening Families Program, which targets 6th-graders and their families to improve parenting skills and family communication have demonstrated positive effects on child-family relationships and avoidance of alcohol, tobacco, and marijuana use for up to 4 years after participation [25] [26]. This shows that the schools and their teachers can play efficient roles in general education and health promotion of children from pre-K to grade 12 .

\section{The Whole School, Whole Community, Whole Child (WSCC) Model}

The WSCC model [22] [27] [28] is a framework developed by the CDC to ensure that the school environment offers opportunities to promote good health and wellness of children and promote school-community collaboration in promoting youth health. This model (Figure 1) shows the various components of the model needed to addresses the health developmental needs of students. WSCC model recognizes schools as the community institutions that touch all families by teaching and nurturing them to be the hope and future of the society. Health and education are related in that healthy students and in safe school environments tend to have higher educational attainment, while poor health results in lower educational achievement and interferes with children's learning process [2] [29] [30]. Health conditions, disabilities, and unhealthy behaviors can all have an effect on educational outcomes. Children who have good education have chances for better health as poor health deprives children both the educational opportunity 


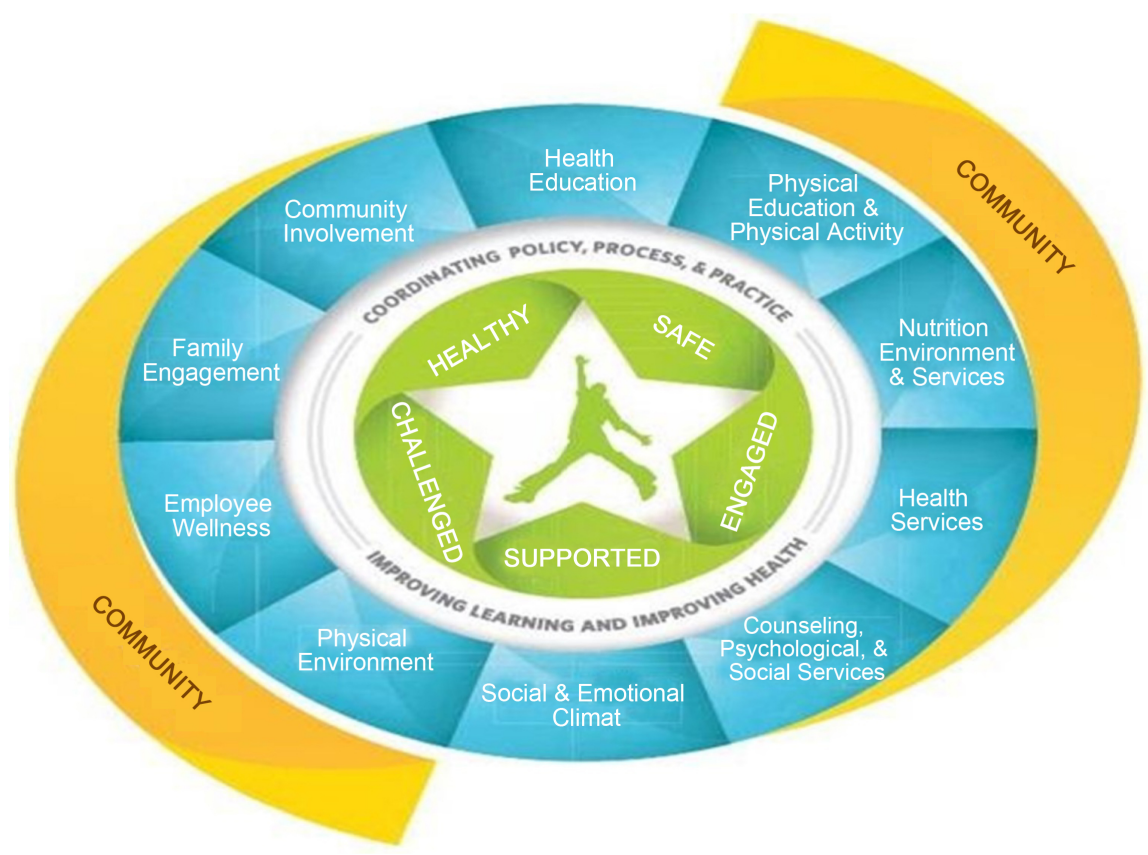

Figure 1. WSCC model. Morse \& Allensworth (2015).

https://onlinelibrary.wiley.com/doi/10.1111/josh.12313

and better health in adulthood. The WSCC model among others has the following benefits: 1) close the gap to unbalanced education of children by focusing on immediate and future needs of the child, 2) engage students in positive health behaviors that enhance physical, socio-emotional and academic growth and development, 3) reduce health disparities, reinforce health promoting behaviors, 4) engage schools, families and communities to adopt and develop lifelong healthy lifestyles, and 5) promotes wellness of education staff.

School therefore is the appropriate environment in which students are taught and provided the opportunity to identify behaviors that adversely impact their health, academic accomplishments and quality of live. Lifestyle diseases will continue to be a public health and national concern if schools are not engaged in health promotion with students from pre-k to grade 12 .

\section{Benefits of Coordinated School Health Education and Promotion Program}

School health education and promotion offers a proactive role in behavioral health education, behavioral-risk intervention and prevention. According to Dr. Raymond Chimezie, President, Health for Schools \& Communities Foundation, "Teaching health education and promotion relentlessly to school children is a preventive measure far more effective and productive than paying for the costs of incarcerating and rehabilitating juveniles". Simply, it is better to have preventive measures in place than running interventionist and rehabilitations programs [31]. If all schools incorporate and teach health education and promotion relentlessly to children in schools their inclination to risky behaviors will be drasti- 
cally reduced. Children will then have the opportunity to develop self-efficacy needed to make rational decisions and avoid behaviors that may have negative health consequences in the future.

Rehabilitative programs after youth incarcerations will ultimately not restore the whole person. Instead, ACLU warned that youth incarceration disrupts and destroys family values by early separation of teens from their families and communities; disrupts their education; exposes them to trauma and violence; and perpetually harms their development [7]. School health promotion is preventive, non-injurious, and more resourceful and eventually will improve kids' health, wellbeing, and development and life prospects.

Evidence about on the benefits of coordinated school health program to students, families, and communities. For report from the California [32] and Colorado [33] Departments of Education highlighted that a coordinated school health program among other benefits: 1) improved student performance and test scores, 2) improve students' ability to learn, 3) decreased risky behaviors, 4) reduce absenteeism, 5) improve staff morale, 6) reduced dropout rates, 7) improve health status, 8) make students successful and contributing members in their communities.

School health program make students allies and leaders in health promotion. Creating meaningful roles for students as allies, decision makers, planners, and peer-educators shows a commitment to prepare them for the challenges of today and the possibilities of tomorrow [27].

For example, when the school health promotion program was launched at Grant Elementary School, Richmond, California, in 2014, a peer-peer group known as Health Ambassadors was formed. The Health Ambassadors took the role of peer health educator and mediated in students conflicts. Among other duties the groups performed were: helping at lunches in the cafeteria by encouraging students to be orderly, encouraging students to choose fruits and vegetables with their lunches, lead physical activities, maintained clean environment, helped yards supervisors to share playing equipment, mentored peers on healthy lifestyles, and participated in school health discussions and daily health tip announcements. This involvement in making a change was both exciting and rewarding to students as they took the change and awareness to their homes and families.

Therefore, investing in school health education and promotion yields more dividends to society than youthful incarceration.

\section{Youth Criminalization and Incarceration: Cost and Health Impact}

According to the Prison Policy Institute, an average of 48,000 youths are held in juvenile facilities due to their involvement in one type of juvenile crime or the other. This Figure 2 includes children as young as 12 years. While $14 \%$ of all youth under 18 in the U.S. are Black, $42 \%$ of boys and $35 \%$ of girls in juvenile facilities are Black. Also, $92 \%$ of youth in juvenile facilities are in locked facilities 


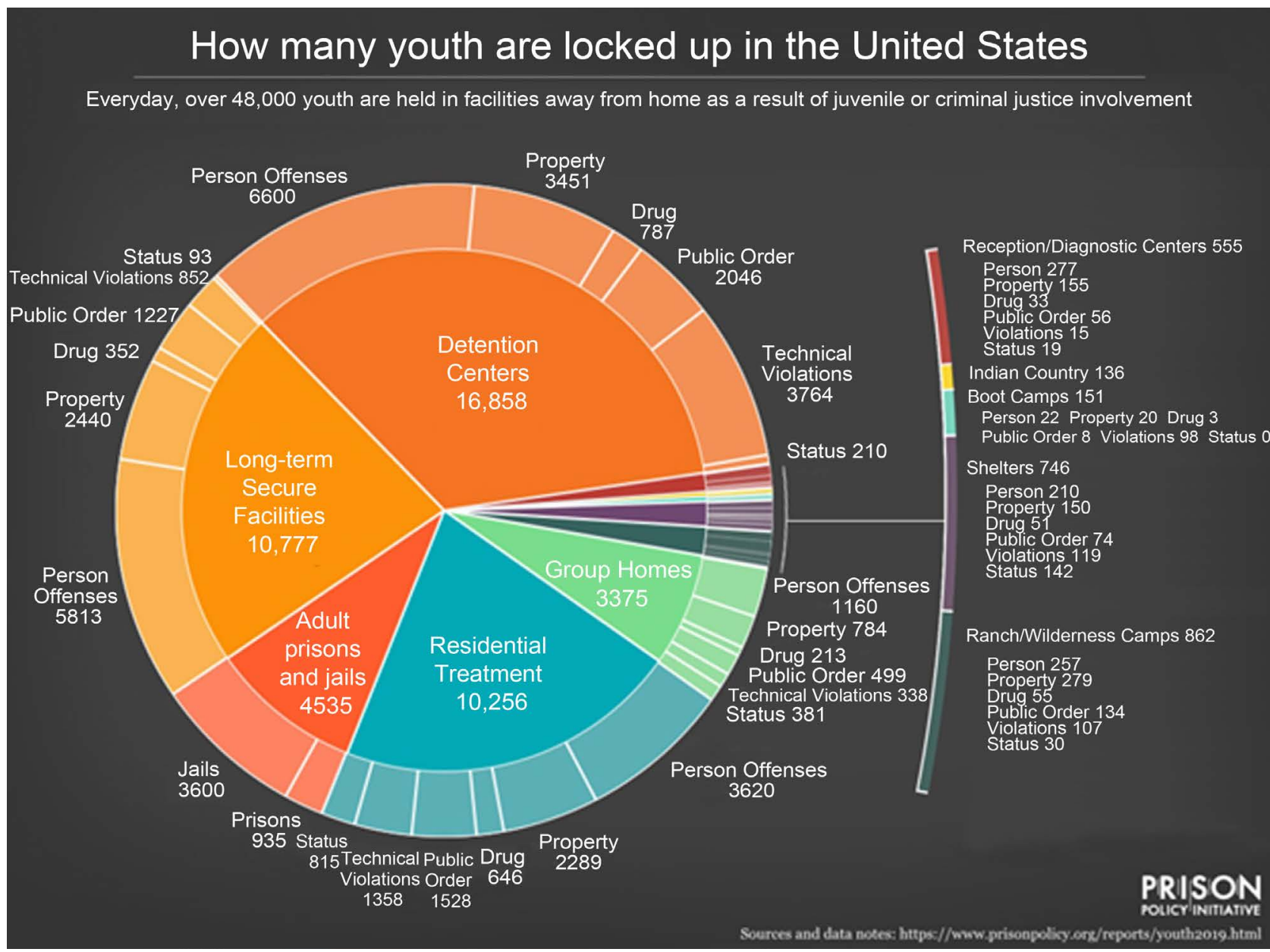

Figure 2. Youth Confinement: The Whole Pie 2019: Youth offences and incarceration types in the United States. Source: https://www.prisonpolicy.org/reports/youth2019.html.

[34]. While most of them, following trials are held in correctional -style restrictive facilities, others are simply held without trials.

Youth incarceration is never an acceptable option to correct or manage youth exuberance misbehaviors. Besides the psychological harm it does to the youth, it is unnecessarily expensive and uneconomical. Community-based school programs designed to control youth risky behaviors can cost about $\$ 75$ a day compared to $\$ 588$, which is the average cost of incarcerating a youth in most states in America which expose them to systemic maltreatment and destruction [35] [36] [37]. An analysis report by the Justice Policy Institute in 2014 stated that about 33 states and the District of Columbia reported an annual cost per youth incarceration of about $\$ 100,000$ [36]. An was reported in L.A. Times, 2016, Garrett Therolf [38] stated that an outcome of Los Angeles county audit found that the average cost of incarcerating a youth has soared to $\$ 233,600$ a year, significantly higher than other comparable jurisdictions. According to the report, in Chicago, the annual cost was $\$ 204,400$ per youth; in San Diego, it was $\$ 127,750$; and in Houston, it was $\$ 84,680$. The report raises a concern for the continued rise even with fallen youth arrest and reduction in the rate of youth incarceration since 
2014. Why has the annual cost for maintaining a confined child remained unchanged over the years! A comparison of the cost for juvenile incarceration and expense to educate a child in the United States education system shows a marked huge gap or difference (See Figure 3 below).

The cost associated with youth incarceration in America has been described as "outrageous" and "lack of support" for programs that keep children on the right part by US Senator Chris Murphy [39]. He remarked that:

"When we lock up a child, not only are we wasting millions of taxpayer dollars, we're setting him or her up for failure in the long run. The system as it exists now is unfair to everyone involved and needs to be changed".

\subsection{North Carolina}

Winston-Salem Journal reported in 2014 that the State of North Carolina spends $\$ 160,000$ a year to incarcerate juveniles, people under 16 years. This report chose data from 46 states and calculated what taxpayers pay indirectly for juvenile incarceration. The estimated amount was $\$ 8$ billion to $\$ 21$ billion a year for long-term juvenile incarceration. This same report noted that North Carolina was among 33 states that spent $\$ 100,000$ or more in juvenile incarceration in the most costly confinement option. As reported, the average cost was $\$ 148,767$ a year compared to North Carolina with $\$ 159,750$ a year [40].

\subsection{California}

In California, more is spent to incarcerate a juvenile than in the education of a

\section{Annual Cost of Juvenile Incarceration vs. Other Youth Investments}

2015 U.S. Dollars

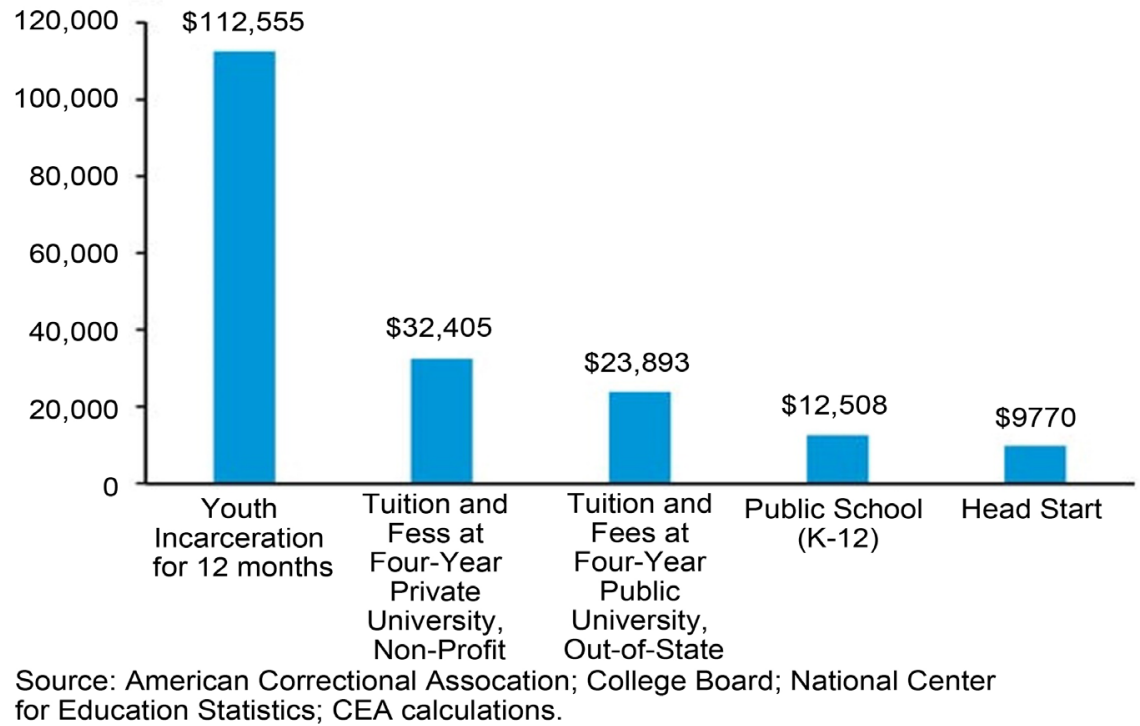

Figure 3. Annual Cost of Juvenile Incarceration vs Other Youth Investment. Source: Juvenile incarceration is way more expensive than tuition at a private university. https://www.businessinsider.com/annual-cost-of-juvenile-incarceration-versus-other-exp enditures-2016-2 
single child per annum. The annual educational expenditure per child remains lower than the national average. Available data from 1988-2015 show that California continues to underspend in per pupil education spending than the national average. In 2015 , per pupil spending statewide $(\$ 10,786)$ was almost $13 \%$ below the average level of spending in the rest of the nation $(\$ 12,346)$. According to data produced by California Budget and Policy Center [41] 2018, in 2015-2016, California ranked 41st among all states in spending per K-12 student after adjusting for differences in the cost of living in each state (see Figure 4 below). California schools spent $\$ 10,291$ per K-12 student in 2015-2016, which is about $\$ 1900$ less than the $\$ 12,252$ per student spent by the nation as a whole. California's spending per student in 2015-2016 was about \$2000 higher than it had been in 2012-2013, at which point California ranked, 50th in the nation. According to the Public Policy Institute of California [42], the annual cost to house a Division of Juvenile Justice (DJJ) ward is $\$ 179,400-$ more than three times the per-inmate cost in the adult system. These funds could be more effectively utilized in health promotion programs that focus on youth development and wellness.

\section{Recommendation}

In view of the fact that school health program has been shown to support and improve children's academic, emotional, and physical development, it is highly recommended that the every school adopts it. This recommendation is based on the fact that school health education program closes the gap in children's growth and education created by poor parenting or lack of, the increasing number of single parenthood in America, and the failure of some schools to offer the education that teach and expose children to healthier lifestyles. School health education makes teachers partners and models for a healthier school environment. This in turn means a better health for students and teachers, increased productivity and higher academic performance, decreased absenteeism, and lower healthcare cost [43]. We recommend as follows: firstly, every school district should ensure that schools in the district from kindergarten to grade 12 adopt their respective state health education curriculum and that there are teachers

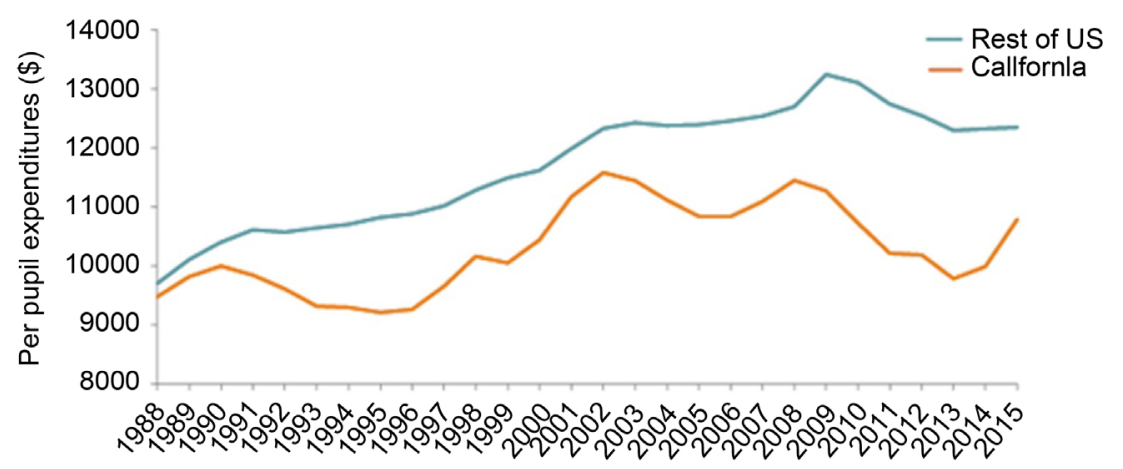

Figure 4. California spending per student 1988-2015. Source: https://www.ppic.org/publication/financing-californias-public-schools/ 
trained and dedicated to support the school health education program [44] [45]. Secondly, based on the agreement of each school, school health promotion should be taught separately at least once a week or integrated in the lessons at every grade level. Thirdly, there should be dedicated health educators employed in every district to help support classroom teachers and train teachers. Fourthly, schools should encourage peer-peer mentoring through the formation of school health ambassadors. Fifthly, every school district should endeavor to build a synergy by partnering with local stakeholders and community members to attract or harmonize resources to meet community needs in terms of youth education, growth, and safety.

\section{Conclusions}

Schools primarily give us the education that equips children with the knowledge to make sound decisions in life. Therefore, a comprehensive school health education program that emphasizes healthy lifestyle choices and skills will set students on the path to recognize and prevent risky behaviors that will impact them negatively both in the present and in adulthood. Students who know the consequences of unhealthy lifestyle choices are likely to think critically before engaging in such practices, for example, tobacco, drug, or alcohol use; early or unprotected sex, unhealthy dietary behaviors or physical inactivity.

They will equally value life and explore their prospects and avoid actions that might end their lives untimely and impact their life dreams. It is equally a gateway to the families to participate, link, and support better and healthy lifestyles. For instance, through the Health Ambassador program at Grant School in Richmond, school and parents were able to link and connect on common preventive issues and equally offered opportunities to refer family members to local resources for help.

Health promotion in schools will help bring policy makers, educators, parents and activists together to address underlying factors that expose children to unhealthy lifestyles as well as draw attention to services or policies that will support healthy lifestyles. This therefore will make school health promotion an inclusive and participatory activity for all stakeholders as the risk factors become a shared problem and finding solutions become equally a shared responsibility.

\section{Conflicts of Interest}

The authors declare no conflicts of interest regarding the publication of this paper.

\section{References}

[1] National Center for Educational Statistics (2020) Fact Sheets. https://nces.ed.gov/fastfacts/display.asp?id=372

[2] Kolbe, L.J. (2019) School Health as a Strategy to Improve Both Public Health and Education. Annual Review of Public Health, 40, 443-463.

https://www.annualreviews.org/doi/10.1146/annurev-publhealth-040218-043727 
https://doi.org/10.1146/annurev-publhealth-040218-043727

[3] Langford, B., Bonell, C., Jones, H., Pouliou, T., Murphy, S., Waters, E., Komro, K., et al. (2015) The World Health Organization's Health Promoting Schools Framework: A Cochranesystematic Review and Meta-Analysis. BMC Public Health, 15, Article No. 130. https://doi.org/10.1186/s12889-015-1360-y

[4] U.S. Centers for Disease Control \& Prevention (2020) About CDC Healthy Schools. https://www.cdc.gov/healthyschools/about.htm

[5] U.S. Centers for Disease Control \& Prevention (2019) Adolescent \& School Health. https://www.cdc.gov/healthyyouth/data/yrbs/index.htm

[6] Children's Defense Fund (2021) State of America's Children 2021: Youth Justice. https://www.childrensdefense.org/state-of-americas-children/soac-2021-youth-justi ce/

[7] American Civil Liberties Union (2021) America's Addiction to Juvenile Incarceration: State by State.

https://www.aclu.org/issues/juvenile-justice/youth-incarceration/americas-addictio n-juvenile-incarceration-state-state

[8] Centers for Disease Control \& Prevention (2020) Whole School, Whole Community, Whole Child (WSCC). https://www.cdc.gov/healthyschools/wscc/index.htm

[9] National Institute on Alcohol Abuse and Addiction (2020) Alcohol Facts and Statistics.

https://www.niaaa.nih.gov/publications/brochures-and-fact-sheets/alcohol-facts-an d-statistics

[10] World Health Organization (2020) Tobacco: Key Facts. https://www.who.int/news-room/fact-sheets/detail/tobacco

[11] Centers for Disease Control \& Prevention (2020) Youth and Tobacco Use. https://www.cdc.gov/tobacco/data_statistics/fact_sheets/youth_data/tobacco_use/in dex.htm

[12] Centers for Disease Control \& Prevention (2021) Preventing Youth Violence. https://www.cdc.gov/violenceprevention/pdf/yv/YV-factsheet_2020.pdf

[13] World Health Organization (2017) Health Promoting School: An Effective Approach for Early Action on NCD Risk Factors.

https://www.who.int/health-topics/health-promoting-schools\#tab=tab_1

[14] The Shattuck Report (1850) Report of a General Plan for the Promotion of General and Public Health. https://biotech.law.lsu.edu/cphl/history/books/sr/Chap3b.pdf

[15] McEvily, B., Jaffee, J. and Tortoriello, M. (2012) Not All Bridging Ties Are Equal: Network Imprinting and Firm Growth in the Nashville Legal Industry, 1933-1978. Organization Science, 23, 547-563. https://doi.org/10.1287/orsc.1100.0633

[16] World Health Organization (2017) Child Health and Development Unit. https://www.who.int/initiatives/making-every-school-a-health-promoting-school

[17] Chimezie, R.O. (2014) Richmond Elementary Introduces Health Initiatives That Spread Citywide.

https://healthfsc.org/latest-news/f/promoting-school-health-in-west-contra-costa-u nified-school-distr

[18] World Health Organization (2021) Making Every School a Health Promoting School. https://www.who.int/initiatives/making-every-school-a-health-promoting-school

[19] Pulimeno, M., Piscitelli, P., Colazzo, S. and Colao, A. (2020) School as Ideal Setting to Promote Health and Wellbeing among Young People. Health Promotion Perspectives, 10, 316-324. https://doi.org/10.34172/hpp.2020.50 
[20] The Institute of Medicine (2012) Accelerating Progress in Obesity Prevention: Solving the Weight of the Nation. The National Academies Press, Washington DC.

[21] Committee on Comprehensive School Health Programs in Grades K-12 (1997) 2 Evolution of School Health Programs. In: Allensworth, D., Lawson, E., Nicholson, L., et al, Eds., Schools \& Health: Our Nation's Investment, National Academies Press (US), Washington DC, 33-76. https://www.ncbi.nlm.nih.gov/books/NBK232693

[22] Galen, E., David, R. and Nilka, M.R. (n.d.) Internal and External Factors That Encourage or Discourage Health-Relevant Behaviors. https://www.orau.gov/cdcynergy/soc2web/Content/activeinformation/resources/He alth_Behavior_Factors.pdf

[23] Centers for Disease Control \& Prevention (2020) Why Schools? Schools: The Right Place for a Healthy Start.

https://www.cdc.gov/healthyyouth/about/why_schools.htm

[24] California Department of Education (2020) What Is Coordinated School Health? https://www.cde.ca.gov/ls/he/cs/csh.asp

[25] Iowa State University (2020) Research: Strengthening Families Program: For Parents and Youth 10-14. https://www.extension.iastate.edu/sfp10-14/research

[26] Office of the Surgeon General (US); National Center for Injury Prevention and Control (US); National Institute of Mental Health (US); Center for Mental Health Services (US) (2001) Chapter 5-Prevention and Intervention. In: Youth Violence. A Report of the Surgeon General. Office of the Surgeon General (US), Rockville, 7. https://www.ncbi.nlm.nih.gov/books/NBK44295/

[27] Morse, L.L. and Allensworth, D.D. (2015) Placing Students at the Center: The Whole School, Whole Community, Whole Child Model. Journal of School Health, 85, 785-794. https://doi.org/10.1111/josh.12313

[28] Centers for Disease \& Control (2020) About CDC Healthy Schools. https://www.cdc.gov/healthyschools/about.htm

[29] Michael, S.L., Merlo, C.L., Basch, C.E., Wentzel, K.R. and Wechsler, H. (2015) Critical Connections: Health and Academics. Journal of School Health, 85, 740-758. https://onlinelibrary.wiley.com/doi/10.1111/josh.12309 https://doi.org/10.1111/josh.12309

[30] Ickovics, J.R., Carroll-Scott, A., Peters, S. M., Schwartz, M., Gilstad-Hayden, K. and McCaslin, C. (2014) Health and Academic Achievement: Cumulative Effects of Health Assets on Standardized Test Scores among Urban Youth in the United States. The Journal of School Health, 84, 40-48. https://doi.org/10.1111/josh.12117

[31] United Nations (n.d.) Youth as a Smart Investment. United Nations, New York. https://www.un.org/esa/socdev/documents/youth/fact-sheets/youth-smart-investme nt.pdf

[32] California Department of Education (2000) Building Infrastructure for Coordinated School Health. https://www.cde.ca.gov/ls/he/cs/documents/blueprintfinal.pdf

[33] Colorado Department of Education (2013) Benefits of Coordinated School Health. https://www.cde.state.co.us/healthandwellness/csh_results

[34] Sawyer, W. (2019) Youth Confinement: The Whole Pie 2019. Prison Policy Initiative, Northampton. https://www.prisonpolicy.org/reports/youth2019.html

[35] Justice Policy Institute (2020) Sticker Shock: The Cost of Youth Incarceration. Justice Policy Institute, Washington DC.

https://justicepolicy.org/research/policy-brief-2020-sticker-shock-the-cost-of-youth 
-incarceration

[36] Justice Policy Institute (2020) Sticker Shock: 2014 to 2020: The Cost of Youth Incarceration.

https://www.justicepolicy.org/uploads/justicepolicy/documents/Sticker_Shock_2020 .pdf

[37] McCarthy, P., Schiraldi, V. and Shark, M (2016) The Future of Youth Justice: A Community-Based Alternative to the Youth Prison Model. National Institute of Justice, Washington DC. https://www.ojp.gov/pdffiles1/nij/250142.pdf

[38] Therolf, G (2016) L.A. County Spends More than $\$ 233,000$ a Year to Hold Each Youth in Juvenile Lockup. Los Angeles Times.

https://www.latimes.com/local/countygovernment/la-me-probation-sticker-shock-2 0160223-story.html

[39] Chris Murphy (2014) To Help Reduce Youth Incarceration, Murphy, Brooker Introduce Bill to Encourage State Policies That Lead to Better Youth Outcomes.

https://www.murphy.senate.gov/newsroom/press-releases/to-help-reduce-youth-inc arcera-

tion-murphy-booker-introduce-bill-to-encourage-state-policies-that-lead-to-betteryouth-outcomes

[40] Hewlett, M. (2014) State Spends $\$ 160,000$ a Year to Lock up a Juvenile. Winston-Salem Journal.

https://journalnow.com/report-state-spends-160-000-a-year-to-lock-up-a-juvenile/a rticle_11ec6d2c-80d4-11e4-b111-832ba6054305.html

[41] California Budget and Policy Center (2018) California's Support for K-12 Education Is Improving, but Still Lags the Nation.

https://calbudgetcenter.org/resources/californias-support-k-12-education-improvin g-still-lags-nation/

[42] Public Policy Institute of California (2014) Juvenile Justice in California. https://www.ppic.org/publication/juvenile-justice-in-california/

[43] Centers for Disease Control \& Prevention (2020) Workplace Health Promotion. https://www.cdc.gov/workplacehealthpromotion/model/evaluation/index.html

[44] Adebayo, A.M., Makinde, G.I. and Omode, P.K (2018) Teachers' Training and Involvement in School Health Programme in Oyo State, Southwest Nigeria. Archives of Basic and Applied Medicine, 6, 9-15.

[45] World Health Organization (1999) Improving Health Education through Schools: National and International Strategies. World Health Organization, Geneva. https://apps.who.int/iris/bitstream/handle/10665/66314/WHO_NMH_HPS_00.1.pd f;jsessionid=16AA16C78314D036B057AFF2ECF17B12? sequence $=1$ 